\title{
Perfectionism and Chinese Gifted Learners
}

\author{
Ricci W. Fong \\ Mantak Yuen \\ The University of Hong Kong
}

Accepted for publication in Roeper Review

Fong, R.W. \& Yuen, M. (2014). Perfectionism and Chinese Gifted. Learners. Roeper Review, 36:2, 81-91, DOI: $10.1080 / 02783193.2014 .884202$

Address correspondence to Ricci W. Fong or Mantak Yuen, Centre for Advancement of Inclusive and Special Education, Faculty of Education, University of Hong Kong, Pokfulam Road, Hong Kong, China. Tel. 852-2241 5828. Fax. 852-2857 4043. E-mail: ricciwfong@ gmail.com or mtyuen@hku.hk

Word count: 9273 (including Abstract \& References) 


\section{AUTHOR BIOS}

Ricci W. Fong, Ph.D., is a Postdoctoral Fellow in the Faculty of Education, The University of Hong Kong. She studied psychology and special education at the University of Hong Kong and she was a primary and secondary school teacher. Her research interests include the impact of perfectionism on Chinese learners, students' social-emotional development, giftedness and talent development, and school counseling. Contact address: Dr. Ricci W. Fong, , Centre for Advancement of Inclusive and Special Education, Faculty of Education, University of Hong Kong, Pokfulam Road, Hong Kong, China. E-mail: ricciwfong@ gmail.com

Mantak Yuen, Ph.D., is an associate professor and Deputy Director of Centre for Advancement of Inclusive and Special Education in the Faculty of Education at the University of Hong Kong. His professional interests are in social-cognitive theory, school counseling, gifted education, life career development, talented youth, children with learning difficulties, and assessment. Contact address: Dr. Mantak Yuen, Centre for Advancement of Inclusive and Special Education, Faculty of Education, University of Hong Kong, Pokfulam Road, Hong Kong, China. E-mail: mtyuen@ hku.hk

\section{Acknowledgements}

The preparation of the paper is in part supported by a Research and Conference Grant from the University of Hong Kong to the first author and the Hong Kong Research Grant Council (HKU $754509 \mathrm{H})$ to the second author. 


\title{
Perfectionism and Chinese Gifted Learners
}

\begin{abstract}
Over the past two decades a wealth of research data on perfectionism has drawn increased attention to the nature and impact of perfectionism on many aspects of student development. Much of the research has explored perfectionism in the gifted student population; but few studies have considered how perfectionism could be perceived differently in students of non-Caucasian descent, and may have different impacts on their learning, development and adjustment. In view of the apparent cultural divide in the research literature, and the emphasis on pursuing perfection within Chinese culture, this paper reviews studies that do address perfectionism in Chinese gifted students. The aim was to offer a cultural perspective for understanding perfectionism in this population and to locate pertinent information to assist identification, counseling interventions and future research.
\end{abstract}

Keywords: Chinese, cultural diversity, gifted students, perfectionism, social-emotional development 


\section{Perfectionism and Chinese Gifted Learners}

Perfectionism can be described as a compulsive striving to achieve extremely high standards, together with a marked tendency to judge one's self-worth on the ability to reach those standards (Fursland, Raykos \& Steele, 2009; Silverman, 1999; Swiatek, 2003). Perfectionism has long been regarded as a personality trait pertinent to research on characteristics of gifted learners (Betts \& Neihart, 1988; Fletcher \& Speirs Neumeister, 2012; LoCicero \& Ashby, 2000; Schuler, 2000; Silverman, 1990; Wang, Fu, \& Rice, 2012). On one hand, the desire to be perfect in every task or endeavour serves as a positive driving force that encourages a gifted student to excel in his or her endeavors (Chan, 2012; Parker \& Mills, 1996; Rice, Leever, Christopher, \& Porter, 2006; Stoeber \& Otto, 2006); but on the other hand, an obsession with perfection can significantly impair learning by causing stress, anxiety and frustration (Adderholdt \& Goldberg, 1999; Chan, 2012; Gnilka, Ashby \& Noble, 2012; Rice et al., 2006; Rice, Richardson, \& Clarke, 2012; Roedell, 1984; Stoeber \& Otto, 2006).

Much of the research effort in recent years has been devoted to debunking myths that have proliferated concerning the nature and effect of perfectionism. This research has led to two different perspectives. One view, attributed mainly to the field of psychology, holds that perfectionist tendencies are primarily destructive rather than beneficial (Burns, 1980; Greenspon, 2000; Pacht, 1984). This negative perspective regards perfectionism as maladaptive, and researchers from the clinical field in particular, have associated extreme and obsessive perfectionism with a wide range of negative and pathological outcomes such as procrastination (Frost, Marten, Lahart, \& Rosenblate, 1990; Mohamadi, Farghadani, \& Shahmohamadi, 2012; Seo, 2008), depression (Black \& Reynolds, 2013; Flett, Galfi-Pechenkov, Molnar, Hewitt, \& Goldstein, 2012; Rice, Leever, Noggle, \& Lapsley, 2007; Wang, 2012), anxiety (Hewitt, Caelian, Flett, Sherry, Collins, \& Flynn, 2002; O’Connor, Rasmussen, \& Hawton, 2010; Rice et al., 2012), eating disorders (Bardone-Cone, Weishuhn, \& Boyd, 2009; Bastiani, Rao, Weltzin, \& Kaye, 1995; Vohs, 
Bardone, Joiner, Thomas, \& Abramson, 1999) and even suicidal ideation (Hewitt, Flett, Sherry, \& Caelian, 2006; Rasmussen, Elliott, \& O'Connor, 2012). These negative outcomes result from the individuals concerned holding unrealistically high expectations of achievement, and feeling excessive concern over mistakes or failures (Frost et al., 1990; Rice \& Slaney, 2002; Stoeber \& Otto, 2006). These negative outcomes can obviously impair an individual's ability to reach his or her maximum potential and develop latent talents. In some cases, negative affective outcomes can lead to significant underachievement and a decrease in motivation, because the student deliberately underachieves as a way of escaping from the 'pains' of perfectionism (Speirs Neumeister, 2004b; Speirs Neumeister \& Finch, 2006; Nugent, 2000; Stoeber, Feast, \& Hayward, 2009).

An alternative (and positive) view is that perfectionism can be benign and adaptive, and is a valuable factor in motivating students to do their best. Supporters of this view (Bieling, Israeli, \& Antony, 2004; Chan, 2007a, 2007b, 2009a, 2010b, 2012; Chang, 2006; Chang, Watkins, \& Banks, 2004; Dunkley, Zuroff, \& Blankstein, 2003; Fletcher \& Neumeister, 2012; Frost, Heimberg, Holt, Mattia, \& Neubauer, 1993; Hamacheck, 1978; Speirs Neumeister, 2007; Speirs Neumeister \& Finch, 2006; Owens \& Slade, 2008; Parker \& Stumpf, 1995; Rice, Ashby, \& Gilman, 2011; Rice \& Preusser, 2002; Rice \& Slaney, 2002; Slade \& Owens, 1998; Stoeber, Hoyle, \& Last, 2013; Stoeber \& Otto, 2006; Stoeber, Stoll, Pescheck, \& Otto, 2008) suggest that striving for perfection can involve setting oneself high goals and developing persistence, resilience and conscientiousness in one's studies. This positive striving for perfection can promote positive outcomes, such as positive affect (Chang, 2006), better social relationships (DiPrima, Ashby, Gnilka, \& Nobel, 2011; Rice et al., 2006; Shim \& Fletcher, 2012), active coping (Weiner \& Carton, 2012), academic satisfaction (Franche, Gaudreau, \& Miranda, 2012), higher self-esteem (Ashby \& Rice, 2002), higher self-efficacy (Chan, 2007b) and growth mindset (Chan, 2012).

Although some researchers still question the adaptive nature of perfectionism (e.g. Flett \& Hewitt, 2006; Greenspon, 2000; Owens \& Slade, 2008; Slade \& Owens, 1998), the current view is that perfectionism actually embodies both maladaptive and adaptive forms (Bieling, Israeli, Smith, 
\& Antony, 2003; Frost et al., 1990; Speirs Neumeister, 2007; Parker, 2000; Rice \& Slaney, 2002;

Stoeber \& Otto, 2006). The challenge for gifted students is to capitalize on the adaptive elements, and to guard against becoming a victim of maladaptive thinking and patterns of responding. The challenge for teachers and counsellors is to help any students who are markedly perfectionistic to understand their own problem and develop appropriate strategies for self-regulation.

\section{Cultural Divide in Perfectionism Research}

Over the past two decades, much has been revealed and debated about the nature, antecedents and outcomes of perfectionism. Apart from the various multidimensional constructs of perfectionism which have been suggested, research has informed us of the apparent association of perfectionism with a wide range of correlates linked to student development and to psychopathological consequences. These findings alert us to a pressing need to recognize perfectionism among our students, and to help them benefit, rather than suffer, from their perfectionistic tendencies. However, it should be noted that the existing research focus has not been equally distributed across cultures and ethnic groups (Castro \& Rice, 2003; Mobley, Slaney, \& Rice, 2005; Wang, Puri, Slaney, Methikalam, \& Chadha, 2012). The majority of studies have focused on European and American students, and thus the findings and implications may not be equally applicable to students of non-Caucasian descent (Chang, 1998; DiBartolo \& Rendón, 2012; Franche et al., 2012; Kawamura, Frost, \& Harmatz, 2002; Nakano, 2009; Stoeber, Kobori, \& Tanno, 2013; Wang, et al., 2012; Wang, Slaney, \& Rice, 2007). Indeed, studies based on Chinese students have revealed differences from the West in the basic concept of perfectionism and its impact on students' development (Chan, 2009a; Cheng, Chong, \& Wong, 1999; Fong \& Yuen, 2011; Wang, Slaney, \& Rice, 2007; Zi, 2003). It is noteworthy that investigating perfectionism in a Chinese context is particularly relevant, because Chinese parents typically value education highly and insist that their children must achieve excellent results in school (Chao, 1994; Ho \& Chiu, 1994; Stankov, 2010; Sue \& Okazaki, 1990; Yoon \& Lau, 2008). They see education as the sure path to 
a good income and prestige in the community. Often this belief results in parents placing a degree of pressure on children that some cultures would probably find excessive. Pressure and high expectations from home, plus the emphasis on achievement in Chinese communities, are key causal factors in many Chinese students becoming perfectionists (Chao, 1994; DiBartolo \& Rendón, 2012; Hamachek, 1978; Ho, 1994; Kashdan \& Yuen, 2007; Kawamura et al., 2002; Ng, Pomerantz, \& Lam, 2007; Salili, 1994).

The three purposes of this paper are: (i) to summarize how perfectionism can be conceptualized among Chinese gifted learners; (ii) to delineate the cultural underpinnings of perfectionism in a Chinese context; and (iii) to discuss how perfectionism impacts on the social and emotional development of gifted Chinese students.

\section{The Chinese View of Perfectionism}

The concept of perfectionism as it applies to Chinese gifted learners can be appreciated through several quantitative and qualitative investigations (e.g., Chan, 2007b, 2009a, 2010a, 2012; Fong \& Yuen, 2013b). These studies suggest that Chinese gifted learners tend to perceive parental pressure, expectations and control in a more positive light than learners in the West. Parental influence contributes in a positive way to the development of their children's perfectionism. They respond positively to having clear goals set for them by their parents, and they feel actively supported. They also recognize that any failures they may have on the road to higher achievement can be remedied by more effort on their part. Difficulties and failures are simply regarded as temporary obstacles that need to be overcome by extra study and persistence. In other words, Chinese gifted learners are likely to display adaptive perfectionism rather than maladaptive perfectionism in their developmental journey.

Chan (2007b) developed a 12-item Positive and Negative Perfectionism Scale (PNPS-12) which taps into perfectionism in terms of its positive/negative and self/other dimensions. In Chan's study, positive perfectionism refers to 'a realistic striving for excellence', and negative 
perfectionism refers to 'the rigid adherence to high personal standards, with similar expectations from others'. While positive and negative perfectionism emerged as independent constructs, there was no clear distinction between self- and other-orientations. Although it is possible that the self-other distinction could be increasingly salient as students get older, the study has revealed that the notion of self and other is collectively perceived among younger Chinese gifted learners. This finding could perhaps be anticipated with reference to previous literature which contends that 'self accomplishment' equally represents 'family accomplishment' in the Chinese context (Hau \& Salili, 1991; Lieber, Fung, \& Leung, 2006; Stankov, 2010). As a result, Chinese gifted learners not only achieve in academic domains for their own satisfaction, but also for the betterment of their families and the community at large.

Parental influence is integral to the development of perfectionism in Chinese gifted learners. In Chinese societies, training from parents begins early in life for children, to instill in them socially desirable values such as filial piety and achievement motivation, in the hope of nurturing later accomplishments that can bring honor to their families (Chao, 1994; McBride-Chang \& Chang, 1998). In addition to learning from an early age that academic success brings certain rewards, Chinese children also learn the consequences of failure. They can sometimes experience shame and guilt induced by their parents' disappointments, and they gradually develop a heightened sensitivity toward others' expectations and criticisms (Chao, 1994; Fung, 1999; Lieber et al., 2006; Stankov, 2010). Factors such as these can be influential in determining whether a student develops adaptive or maladaptive perfectionism.

Our understanding of this phenomenon was helped by a study conducted in Hong Kong (Chan, 2009a). The study examined the psychometric properties of a Chinese-translated version of the Multidimensional Perfectionism Scale (FMPS; Frost et al., 1990). Chan used a sample of 380 Chinese gifted students aged 9 to 14 years. The results indicated that perfectionism could be interpreted in terms of the personal standards they set for their own performance, the parental expectations and parental criticisms they experience, their concern over mistakes and doubts, as 
well as their emphasis on organization. What distinguished this Chinese gifted sample from the previous studies involving subjects of average ability is that these students could discern the difference between parental criticism and parental expectation. More specifically, parental expectation was associated with healthy (adaptive) perfectionism - because it helps to set goals and it implies parental interest and support — whereas parental criticism (with its connotations of rebuke) was associated with unhealthy (maladaptive) perfectionism. The findings suggest that high parental expectations could be facilitative in the pursuit of academic excellence among these students. It can be deduced that Chinese gifted students are more able than others to recognize parental expectation as a positive driving force that motivates them to strive for perfection. In fact, many researchers believe that parental expectations and strictness are perceived to be expressions of love and care in Chinese culture (Chao, 1994; Hau \& Salili, 1991; Peterson, Cobas, Bush, Supple, \&Wilson, 2004; Tobin, Wu, \& Davidson, 1989). The pursuit of perfection is thus seen to be influenced by cultural norms that differ between East and West.

The concept of perfectionism was also explored by Fong and Yuen (2013b) who interviewed 21 academically gifted children in Hong Kong. Adding to Chan's (2009a) findings, Fong and Yuen's study confirmed that Chinese academically gifted students were able to acknowledge the positive motive behind their parents' high expectations and stringent control. Their reluctance to disappoint their parents, and the early training they received from their parents (e.g., conscientious study habits, and early exposure to foreign language), have shaped their goals and contributed to their academic success over the years. More importantly, any failures they might experience are regarded as valuable lessons, rather than a source of shame. This sample of gifted children generally believed that previous mistakes inform them of weaknesses they need to address, and that these weaknesses can be overcome with persistent hard work. From the data obtained in this study, it seems that Chinese gifted students tend to evaluate their own performances and to invite others' opinions, as they strive to master each new area of study. This can certainly be seen as an adaptive form of perfectionism. 
Other studies conducted by Chan (2007b, 2009a, 2010b) provide empirical evidence to support the conjecture that Chinese gifted learners tend to be adaptive perfectionists. Using cut-off scores, Chan (2007b) discovered that an impressive $70.5 \%$ to $94.3 \%$ of participants could be classified as positive (adaptive) perfectionists while only $6.7 \%$ to $31.2 \%$ were negative perfectionists. Consistently, Chan (2009a) found that 'healthy' (adaptive) perfectionists made up the largest group (44\%) in his Chinese gifted sample, whereas maladaptive perfectionists made up the smallest group (27\%).

Chan (2010b) also investigated the typology of perfectionists among 320 gifted and 882 non-gifted Chinese students in Hong Kong, using a Chinese version of the Almost Perfect Scale Revised (APS-R; Slaney, Rice, Mobley, Trippi, \& Ashby, 2001). He identified three perfectionist types_adaptive perfectionist, maladaptive perfectionist and non-perfectionist_-via median splits and clustering procedures. Adaptive perfectionists reported high scores on the High Standards and Order subscales, and low scores on the Discrepancy subscale. These students pursue high performance standards and emphasize tidiness and organization without being excessively concerned when they fail to live up to their performance expectations. Conversely, maladaptive perfectionists are characterized by their high scores on the Discrepancy subscale. In other words, these students spare themselves little allowance for mistakes and failures. Consistent with previous findings in the West (LoCicero \& Ashby, 2000; Parker, 1997; 2000; Parker \& Mills, 1996), this sample of Chinese gifted learners were not only more perfectionistic than their Western peers but also tended to endorse adaptive perfectionism rather than maladaptive perfectionism.

In a later study which examined how different classification approaches will affect perfectionist types, Chan (2010b) again highlighted the adaptive nature of Chinese gifted perfectionists. By administering the Chinese version of the Almost Perfect Scale - Revised (Slaney et al., 2001) to 111 academically gifted students in Hong Kong, Chan (2010b) classified the participants into different perfectionist groups using three approaches: (i) the rational approach (using cut-off scores to differentiate high and low scores), (ii) the empirical approach (using 
clustering procedures) and (iii) the self-reported approach (requiring students to endorse a statement that was descriptive of themselves). Again, it was concluded that healthy (adaptive) perfectionists constitute the largest group, accounting for $23 \%$ to $70 \%$ of the participants, depending of the classification scheme employed. Maladaptive perfectionists accounted for $14 \%$ to $41 \%$ of the participants. When these studies are considered together and then compared with previous US studies (e.g. Parker, 1997; Schuler, 2000), more Chinese gifted learners appear to be adaptive perfectionists despite their commonly high exposure to authoritarian parenting and criticism. In some cultures, such parenting is believed to promote maladaptive perfectionism (Enns, Cox, \& Clara, 2002; Kawamura et al., 2002; Speirs Neumeister, 2004). The above studies suggest that perfectionism tends to appear in a more positive and productive form among Chinese gifted learners. Any failures they may have in meeting parental or social expectations at times may be temporarily distressing, but longer-term they seem to serve as a positive stimulus that can motivate the students to strive harder for perfection (Wang, Yuen, \& Slaney, 2009).

The conception of perfectionism in Chinese culture may differ from that pertaining in the West, where 'being perfect' almost implies never making mistakes. Dweck, Chiu and Hong (1995) remarked that Chinese students are more likely than their Western counterparts to believe that intelligence is malleable. More recently, Chan (2012) looked into the mindset theories endorsed by different types of perfectionists among 251 Chinese gifted students, with their ages ranging from 9 to 18 . The notion of mindset basically refers to the view that one adopts for oneself. Individuals who adopt a growth mindset believe that their personal qualities are malleable and can be cultivated with more efforts. They are dedicated to learning, accepting new ideas and stretching themselves. Conversely, those who adopt a fixed mindset will tend to believe that their personal qualities are "carved in stone" and they cannot be changed regardless of the amount of effort expended. These individuals therefore tend to channel their attention to prove themselves to others over and over instead of working on their qualities for a better self (Dweck, 2007). We can easily see the relevance of mindsets to the study of perfectionism, especially in the 
Chinese context where effort is the hallmark of success. Using the Chinese APS-R to classify students' perfectionist types (Chan, 2010b), Chan (2012) again found more healthy perfectionists than unhealthy perfectionists among Chinese gifted students. Besides, while both groups reported high scores on growth mindset and low scores on fixed mindset, the healthy perfectionists hold a stronger growth mindset than the unhealthy ones, who are more inclined to adopt a fixed mindset. The findings are not very surprising when taking into account what has been found in previous studies both in the East and West (e.g. Ablard \& Parker, 1997; Bieling et al., 2004; Chan, 2007b; 2009b; Enns et al., 2002; Hamacheck, 1978; Hau \& Salili 1991; Speirs Neumeister, 2004b). Chan (2012) nevertheless reiterated that what can make perfectionist tendencies unhealthy is not the actual striving for perfection, but the discrepant perception between expectation and performance (Stoeber \& Otto, 2006). Particularly in the East, the underlying value of perfectionism may hinge upon a desire to self-improve through expending efforts until perfection is achieved, partly in an attempt to fulfill social or familial goals. We can further conjecture that family and society at large play crucial roles in creating and sustaining Chinese students' perfectionism. We can also conjecture that perfectionism is more facilitative than deleterious to Chinese gifted learners.

\section{The Cultural Origin of Chinese Perfectionism}

What makes the conception and impact of perfectionism different in the Chinese context? In terms of conception, many researchers attribute the cultural differences mainly to the Confucian root of Chinese culture which still influences the Chinese today (Chao, 1994; Leiber et al., 2006). Filial piety, lifelong learning and social harmony are a few of the core values highlighted in The Analects of Confucius, a compilation of conversation between Confucius and his students. This volume has been regarded as the 'book of wisdom' and it has governed the behaviors of all social roles, from being somebody's child to being the ruler of a state in Ancient China (Watson, 2007). As all individuals are members of a larger social hierarchy, Chinese children are expected to obey, respect and honor their parents and family through personal accomplishments, especially those in 
academic domain (Ho, 1994). In Ancient China, a child achieving academic excellence in the civil examination would bring honor and great fortune to the entire family line or even the whole village. On the other hand, it is also parents' duty to train their children to adopt socially desirable values to maintain social harmony and contribute to the community at large (Chao, 1994). Chinese learners are taught to strive to become a 'better self' by learning through self-reflection, external evaluation of self, and observation of others; and are also taught that effort, rather than innate ability, is the key to success (Hau \& Salili, 1991; Tweed \& Lehman, 2002).

Li (2002) has developed a Chinese model of learning in light of the Confucian tradition through collecting written accounts of 'ideal' Chinese learners from 122 Chinese college students in mainland China. For these Chinese students, learning refers to a process of self-perfection, which involves seeking knowledge, cultivating a passion for lifelong learning, fostering diligence, enduring hardship, persistence, concentration, putting in great effort even in the face of barriers, and feeling shameful and guilty for one's lack of desire to learn. To date, achieving academic excellence is still regarded as the most important duty of Chinese learners (Kashdan \& Yuen, 2007). The impact of Confucianism is still significant despite the change of eras. Hence to this end, Chinese children are accustomed to taking on a lifelong quest for excellence, which is not solely or primarily driven by personal interests, but substantially by social or familial goals (Chao, 1994; Li, 2002; Salili, 1994; Stankov, 2010).

Research literature from the West commonly attributes the formation of perfectionism in children to parental influence (Ablard \& Parker, 1997; Hamachek, 1978; Miller, Lambert, \& Speirs Neumeister, 2012; Robinson, 2002; Speirs Neumeister, 2004a, Speirs Neumeister, Williams, \& Cross, 2009). According to Preusser, Rice and Ashby (1994), Asian students may perceive their perfectionism as stemming from having an obligation to make their parents feel proud of them. In light of Confucian values, family influences along with the pursuit of social cohesion also steer Chinese gifted learners toward perfectionism. To Chinese gifted learners, the goal for learning and success and the social goal of meeting family expectations and glorifying one's family are 
valued over the goal simply to prove oneself to others (Chan, 2008). Chan (2009b) has also examined the associations between perfectionism and goal orientations among 315 Chinese gifted children and adolescents in Hong Kong. The two preferred goals-learning goal and social goal—are found to predict positive perfectionism, whereas performance and avoidance goals predict negative perfectionism. In other words, Chinese gifted learners who aim to develop self and meet social expectations tend to be positive perfectionists; and those who aim to demonstrate their ability to others and avoid chances of revealing personal weaknesses tend to be negative perfectionists. The results are consistent with the emphasis on lifelong learning, family obligations and achievement in Confucian teachings (Ho, 1994; Salili, 1994; Stankov, 2010). Although Chinese gifted learners seem more active in pursuing high accomplishment even in the face of social stressors, such as others' high expectations attributable to their gifted label and previous accomplishments, they are not exempted from the social and emotional turmoil that challenges Western gifted learners (Hebert \& Speirs Neumeister, 2002; Neihart, 1999; Peterson, 2009; Silverman, 1993; Winner, 2000). If understanding the conception of perfectionism among Chinese gifted learners is the first crucial step to enhancing their well-being, information regarding how perfectionism influences their social and emotional development is also of importance.

\section{Perfectionism and Social-Emotional Development}

Peterson (2009) has pointed out that the social and emotional needs of gifted students are easily neglected because they are usually doing very well and experiencing success in all areas. Among the potential social-emotional challenges faced by gifted learners, perfectionism is noted as one of the most common in Western research literature, alongside asynchronous development, social difficulties, heightened sensitivity, and conflicting gender role expectations (Hebert \& Speirs Neumeister, 2002; Neihart, Reis, Robinson, \& Moon, 2002; Orange, 1997; Peterson, 2009). In the East, perfectionism is deemed influential to the social-emotional development of Chinese gifted learners, in the same way that it is influential in the West. On the whole, perfectionism in any 
Chinese learners, gifted or otherwise, is found to be related to their psychological well-being (Castro \& Rice, 2003; Chan, 2007a; Wang et al., 2007; Wang, Yuen et al., 2008; Yoon \& Lau, 2008), self-perceptions (Chan, 2007b; Fong \& Yuen, 2013a), interdependence, and parent-child relations (Fong \& Yuen, 2013a, 2011c; Yoon \& Lau, 2008). However, few studies have attended specifically to this issue in gifted learners. The small body of extant research focusing on Chinese gifted learners has examined associations between perfectionism and variables vital to the social-emotional development of gifted learners, such as self-efficacy (Chan, 2007b; Fong \& Yuen, 2013a), social connectedness (Fong \& Yuen, 2013a, 2013b), goal orientations (Chan, 2009b), coping strategies (Chan, 2007a), and subjective well-being (Chan, 2007b). Although the existing research studies cited here on the Chinese gifted population were based on Hong Kong students, the findings can nevertheless offer reliable references for understanding the role of perfectionism in the interpersonal and intrapersonal development of Chinese gifted learners elsewhere.

Along the developmental journey, gifted learners often have to face social-emotional challenges because they may have uneven development in various domains (Chan, 2006; Gross, 2002; Lerouxa \& Levitt-Perlman, 2000; Peterson, 2009; Silverman, 1993; Tannenbaum, 1997). The more highly gifted they are, the more social difficulties they may have to overcome in order to fit into the social world (Burks, Jensen, \& Terman, 1930; Dauber \& Benbow, 1990; Hollingworth, 1942; Peterson, 2009). Hebert and Speirs Neumeister (2002) suggest that among the social-emotional issues concerning gifted learners the most common are loneliness (due to the lack of understanding and like-minded companions), their perfectionist tendencies, overt precocity, and the struggles of fulfilling gender role expectations, and preserving their creativity. Like Western gifted learners, Chinese gifted learners are also confronted with various challenges, such as concerns about being different, relationship concerns, and others related to maladaptive perfectionism (Chan, 2003a, 2003b, 2007a).

Guided by previous investigations on the social coping strategies adopted by Western gifted learners (Colangelo \& Kelly, 1983; Gross, 1989; Pfeiffer \& Stocking, 2000; Piechowski, 1997; 
Swaitek, 1995), Chan (2003a, 2004, 2005) found that Chinese gifted learners generally use coping strategies to minimize their differences with average peers, and to facilitate social interaction with peers. To these ends, coping strategies that Chinese gifted learners typically apply include: denying and hiding their giftedness, discounting popularity, attempting avoidance, seeking conformity, helping others, and involvement in activities. Regardless of age, Chinese gifted learners tend to use social-interaction coping strategies more than minimizing-differences strategies. This tendency is thought to be consistent with the value of social harmony and interdependence in the Chinese culture (Chan, 2005). Later, to examine the relationship between perfectionism and coping strategies, Chan (2007a) administered the Chinese Ways of Coping Questionnaire (CWCQ; Chan, 1994) to 298 Chinese gifted students in Hong Kong. The results reveal that the use of active coping strategies (seeking support and emotion ventilation, and rational problem solving) predict students' endorsement of positive perfectionism. In contrast, passive coping strategies (resigned distancing and passive wishful thinking) predict students' endorsement of negative perfectionism. The investigator however noted that the tendencies and associations found in the study were tapped from high academic achievers nominated by their teacher, and therefore these students could be well adjusted in social-emotional domains (Chan, 2003a, 2005, 2007a). Empirical evidence has yet to verify whether the findings are valid among other Chinese gifted students, for instance those who encounter specific learning difficulties in the academic domain, and underachievers.

In general, these studies suggest that parents, educators and counseling practitioners should encourage Chinese gifted students to engage more actively in social interactions with people in their social circles and discourage them from hiding their talents and avoiding risk-taking activities. In this regard, helping gifted students clarify and differentiate between social and personal expectations will be important.

By employing structural equation modeling on data collected from 1425 academically talented and average primary school students in Hong Kong, Fong and Yuen (2013a) have found 
that students' perfectionism can predict their perceived connectedness to family and school.

Together with a follow-up qualitative investigation in which 21 academically talented students were interviewed (Fong \& Yuen, 2013b), the two studies showed that perfectionist characteristics of Chinese gifted learners (persistent effort, positive and negation reactions to one's performance, and the need for social admiration) make them feel more connected to their family, teachers, peers and school. This may be because the different social parties offer them recognition and support in response to their needs. And in times of disappointment, they will share their negative thoughts with their significant others and seek advice or actual assistance from others. In this connection, the two studies testify that Chinese gifted learners are applying active coping strategies even at primary school age. Moreover, in line with the Confucian tradition, students reported attempts of gaining admiration and maintaining family harmony via their diligence, and eventually, their accomplishments.

Another major finding of Fong and Yuen (2013a, 2013b) is that students' perfectionism can directly and indirectly predict their academic self-efficacy via their perceived social connectedness. On one hand, their perfectionist characteristics allow them to feel more competent in applying their academic skills. Their persistent effort and compulsive study habits ensure eventual success (Hau \& Salili, 1991). Any negative emotions they may feel toward previous failures alert them to identify and work on their weaknesses. With their need for social admiration, their academic self-efficacy is strengthened with every appraisal and sign of recognition they receive from others.

On the other hand, a sense of social connectedness gained under the influence of their perfectionism, in turn, assures them the availability of social support and fosters their self-efficacy in applying academic skills.

While earlier work of Chan (2007b) found that perfectionism can directly predict students' subjective well-being, their general self-efficacy also appears to be a reliable mediator in the predictive association between perfectionism, life satisfaction, and affect among Chinese gifted learners. Gifted learners who display positive perfectionism tend to feel more competent in 
handling stressful situations. This perceived competence enables them to experience satisfaction in life and positive affect. Conversely, those who possess negative perfectionism tend to be less confident in dealing with difficult situations, and thereby are less able to gain life satisfaction and positive affect.

Taken together, the above studies reinforce a view that perfectionism in gifted students is not automatically a malignant trait, and should certainly not be eliminated completely. Where necessary, counseling goals should center on reinforcing students' characteristics of adaptive perfectionism, while diminishing those of maladaptive perfectionism (Kottman \& Ashby, 2000; Mofield \& Chakraborti-Ghosh, 2010; Nugent, 2000). To this end, it is essential that counseling approaches should also address any relevant socio-cultural factors associated with the students concerned (Duan \& Wang, 2000; Lau, 2000). For instance, in Chinese communities, fostering students' social connectedness, and guiding them to focus on effort, could be effective anchor points for steering them to benefit from the adaptive aspects of perfectionism.

\section{CONCLUSION}

The past decade of research into perfectionism among Chinese gifted learners has suggested that the conception of perfectionism in terms of dimensionality and typology is somewhat similar in some respects between East and West, but there are some important differences. One can define the Chinese view of perfectionism by the performance standards pursued, sensitivity and response toward failures, and parental influences. In the Chinese gifted population, not only is perfectionism more prevalent among gifted students, compared to the situation in the West, but adaptive perfectionism also appears to be more dominant than maladaptive perfectionism. Perfectionism as exemplified by many Chinese gifted learners appears to stem from a more collectivistic cultural root, and it is associated with goal orientations (Chan, 2009b), coping strategies (Chan, 2007a), self-efficacy (Chan, 2007b; Fong \& Yuen, 2013a), subjective well-being 
(Chan, 2007b), and social connectedness (Fong \& Yuen, 2013a, 2013b); but the picture we now see is incomplete.

The existing literature points to the distinctive cultural roots influencing the nature of perfectionism in the East, indicating that it is more socially oriented than in the West. However, high achievement is also meaningful to oneself, as much as it is to one's family and the community. Chinese gifted learners basically see perfection as a consequence of persistent effort, active learning from mistakes, and from feedback from others, with the indispensable involvement of one's family and other social parties.

It is obvious that the construct of perfectionism has been under-researched among Chinese gifted learners. While the existing studies suggest that Chinese gifted learners could be less susceptible to the detrimental effects of maladaptive perfectionism when compared to their Western counterparts, there are still information gaps pending investigation and verification. For example, we are not sufficiently informed of how perfectionism impacts on Chinese gifted learners, as most studies have involved samples of ordinary Chinese students (Cheng, 2001; Cheng et al., 1999; Fong \& Yuen, 2011; Wang et al., 2007; Wang, Yuen, et al., 2009; Yoon \& Lau, 2008; Zhang, Gan, \& Cham, 2007; Zi, 2003). Nor have we investigated perfectionism as a possible cause of underachievement among the potentially gifted. While the Chinese's beliefs that effort determines achievement (Hau \& Salili, 1991) and that intelligence is not a fixed entity (Dweck et al., 1995), may considerably contribute to their motivation to pursue excellence, little is unknown as to how this growth mindset is associated with the typology of perfectionism in the Chinese context.

Given the importance of parental influence in Chinese students' development of perfectionism, it is surprising that no study to date has looked into parents' own perfectionistic tendencies, or how parents regard their children's perfectionism. Another surprising research gap is the lack of data on Chinese perfectionism in terms of self-oriented, other-oriented and socially-prescribed perfectionism. A possible paradigm to use might be Hewitt's 
Multidimensional Perfectionism Scale (HMPS; Hewitt and Flett, 1991), but so far this has mostly been used in the psychopathological domain.

Fundamentally, it is also worth considering whether the existing perfectionism scales, including the HMPS (Hewitt and Flett, 1991) and FMPS (Frost et al., 1990), have overemphasized the negative aspect of perfectionism (Chan, 2007b; 2012). It is also important to consider whether at times the negative outcomes attributed to perfectionism may eventually outweigh the benefits it could bring (Flett \& Hewitt, 2006; Greenspon, 2000). More information on such issues will be essential for research innovation and strategic planning of counseling approaches in schools. While effective strategies for assisting perfectionist learners have been proposed and established in Western literature, application of the strategies to Chinese gifted learners is barely documented. Issues worthy of investigation include: Is play therapy useful in dealing with young Chinese gifted learners (Ashby, Kottman, \& Martin, 2004)? Does gender make a difference to perfectionist tendency (Flett, Hewitt, \& Singer, 1995; Stoeber \& Stoeber, 2009)? Is perfectionism perceived differently among students gifted in different domains (Stoeber \& Eismann, 2007; Stornelli, Flett, \& Hewitt, 2009)?

Given the relatively abundant perfectionism research literature from Western societies, it is easy for Chinese parents and educators to rely too much on Western-based information and approaches in dealing with gifted perfectionists in the Chinese context. This is unwise, given the significant cultural differences. More research effort is warranted to identify the cultural-specific needs of Chinese gifted learners, as well as to examine the applicability of Western counseling approaches. Every step of research advancement will count towards the well-being of the Chinese gifted population. 


\section{REFERENCES}

Ablard, K. E., \& Parker, W. D. (1997). Parents' achievement goals and perfectionism in their academically talented children. Journal of Youth and Adolescence, 26(6), 651-667.

Adderholdt, M., \& Goldberg, J. (1999). Perfectionism: What's bad about being too good? Minneapolis, MN: Free Spirit.

Ashby, J. S., Kottman, T., \& Martin, J. L. (2004). Play therapy with young perfectionists. International Journal of Play Therapy, 13(1), 35-55.

Ashby, J. S., \& Rice, K. G. (2002). Perfectionism, Dysfunctional Attitudes, and Self Esteem: A Structural Equations Analysis. Journal of Counseling \& Development, 80(2), 197-203.

Bardone-Cone, A. M., Weishuhn, A. S., \& Boyd, C. A. (2009). Perfectionism and bulimic symptoms in African American college women: Dimensions of perfectionism and their interactions with perceived weight status. Journal of Counseling Psychology, 56(2), 266.

Bastiani, A. M., Rao, R., Weltzin, T., \& Kaye, W. H. (1995). Perfectionism in anorexia nervosa. International Journal of Eating Disorders, 17(2), 147-152.

Betts, G. T., \& Neihart, M. (1988). Profiles of the gifted and talented. Gifted Child Quarterly, 32(2), 248-253.

Bieling, P.J., Israeli, A.L., \& Antony, M.M. (2004). Is perfectionism good, bad, or both? Examining the perfectionism, construct. Personality and Individual Differences, 36(6), 1373-1385.

Bieling, P. J., Israeli, A., Smith, J., \& Antony, M. M. (2003). Making the grade: The behavioral consequences of perfectionism in the classroom. Personality and Differences, 35, 163-178.

Black, J., \& Reynolds, W. M. (2013). Examining the relationship of perfectionism, depression, and optimism: Testing for mediation and moderation. Personality and Individual Differences, $54(3), 426-431$.

Burks, B. S., Jense, D. W., \& Terman, L. M. (1930). The promise of youth: Vol.3: Genetic studies of genius. Stanford, CA: Stanford University Press.

Burns, D. D. (1980). The perfectionist's script for self-defeat. Psychology today, 14(6), 34-52. 
Castro, J. R., \& Rice, K. G. (2003). Perfectionism and ethnicity: Implications for depressive symptoms and self-reported academic achievement. Cultural Diversity and Ethnic Minority Psychology, 9(1), 64-78.

Chan, D. W. (1994). The Chinese Ways of Coping Questionnaire: Assessing coping in secondary school teachers and students in Hong Kong. Psychological Assessment, 6(2), 108-116.

Chan, D. W. (2003a). Adjustment problems and multiple intelligences among gifted students in Hong Kong: The development of the revised Student Adjustment Problems Inventory. High Ability Studies, 14(1), 41-54.

Chan, D. W. (2003b). Assessing adjustment problems of gifted students in Hong Kong: The development of the Student Adjustment Problems Inventory. Gifted Child Quarterly, 47(2), 107-117.

Chan, D. W. (2004). Social coping and psychological distress among Chinese gifted students in Hong Kong. Gifted Child Quarterly, 48(1), 30-41.

Chan, D. W. (2005). The structure of social coping among Chinese gifted children and youths in Hong Kong. Journal for the Education of the Gifted, 29(1), 8-29.

Chan, D. W. (2006). Adjustment problems, self-efficacy, and psychological distress among Chinese gifted students in Hong Kong. Roeper Review, 28(4), 203-209.

Chan, D. W. (2007a). Perfectionism among Chinese gifted students in Hong Kong: Relationships to coping strategies and teacher ratings. Gifted Education International, 23, 289-300.

Chan, D. W. (2007b). Positive and negative perfectionism among Chinese gifted students in Hong Kong: Their relationships to general self-efficacy and subjective well-being. Journal for the Education of the Gifted, 31(1), 77-102.

Chan, D. W. (2008). Goal orientations and achievement among Chinese gifted students in Hong Kong. High Ability Studies, 19(1), 37-51. 
Chan, D. W. (2009a). Dimensionality and typology of perfectionism: The use of the Frost Multidimensional Perfectionism Scale with Chinese gifted students in Hong Kong. Gifted Child Quarterly, 53(3), 174.

Chan, D. W. (2009b). Perfectionism and goal orientations among Chinese gifted students in Hong Kong. Roeper Review, 31(1), 9-17.

Chan, D. W. (2010a). Healthy and unhealthy perfectionists among academically gifted Chinese students in Hong Kong: Do different classification schemes make a difference? Roeper Review, 32, 88-97.

Chan, D. W. (2010b). Perfectionism among Chinese gifted and non-gifted students in Hong Kong: The use of the Revised Almost Perfect Scale. Journal for the Education of the Gifted, 34(1), $68-98$.

Chan, D. W. (2012). Life satisfaction, happiness, and the growth mindset of healthy and unhealthy perfectionists among Hong Kong Chinese gifted students. Roeper Review, 34, 224-233.

Chang, E. C. (2006). Conceptualization and measurement of adaptive and maladaptive aspects of performance perfectionism: Relations to personality, psychological functioning, and academic achievement. Cognitive Therapy and Research, 30(6), 677-697.

Chang, E. C., Watkins, A. F., \& Banks, K. H. (2004). How adaptive and maladaptive perfectionism relate to positive and negative psychological functioning: Testing a stress-mediation model in black and white female college students. Journal of Counseling Psychology, 51, 93-102.

Chao, R. (1994). Beyond parental control and authoritarian parenting style: Understanding Chinese parenting through the cultural notion of training. Child Development, 65, 1111-1119.

Cheng, S. K. (2001). Life stress, problem solving, perfectionism, and depressive symptoms in Chinese. Cognitive Therapy and Research, 25(3), 303-310.

Cheng, S. K., Chong, G. H., \& Wong, C. W. (1999). Chinese Frost Multidimensional Perfectionism Scale: A validation and prediction of self-esteem and psychological distress. Journal of Clinical Psychology, 55(9), 1051-1061. 
Colangelo, N., \& Kelly, K. R. (1983). A study of student, parent, and teacher attitudes toward gifted programs and gifted students. Gifted Child Quarterly, 27, 107-110.

Dauber, S. L., \& Benbow, C. P. (1990). Aspects of personality and peer relations of extremely talented adolescents. Gifted Child Quarterly, 34, 10-14.

DiBartolo, P. M., Rendón, M. J. (2012). A critical examination of the construct of perfectionism and its relationship to mental health in Asian and African Americans using a cross-cultural framework. Clinical Psychology Review, 32, 139-152.

DiPrima, A. J., Ashby, J. S., Gnilka, P. B., \& Noble, C. L. (2011). Family relationships and perfectionism in middle school students. Psychology in the Schools, 48(8), 815-827.

Duan, C., \& Wang, L. (2000). Counseling in the Chinese cultural context: Accommodating both individualistic and collectivistic values. Asian Journal of Counselling, 7, 1-21.

Dunkley, D., Zuroff, D., \& Blankstein, K. (2003). Self-critical perfectionism and daily affect. Journal of Personality and Social Psychology, 84, 234-252.

Dweck, C. S. (2007). Mindset: The new psychology of success. US: Ballantine Books.

Dweck, C. S., Chiu, C., \& Hong, Y. (1995). Implicit theories: Elaboration and extension of the model. Psychological Inquiry, 6(4), 322-333.

Enns, M. W., Cox, B. J., \& Clara, I. (2002). Adaptive and maladaptive perfectionism: Developmental origins and association with depression proneness. Personality and Individual Differences, 33, 921-935.

Fletcher, K. L., \& Speirs Neumeister, K. L. (2012). Research on perfectionism and achievement motivation: Implications for gifted students. Psychology in the Schools, 49(7), 668-677.

Flett, G. L., Galfi-Pechenkov, I., Molnar, D. S., Hewitt, P. L., \& Goldstein, A. L. (2012). Perfectionism, mattering, and depression: A mediational analysis. Personality and Individual Differences, 52(7), 828-832.

Flett, G. L. \& Hewitt, P. L. (2006). Positive versus negative perfectionism in psychopathology: A comment on Slade and Owens's Dual Process Model. Behavioral Modification, 30, 472-495. 
Flett, G. L., Hewitt, P. L., \& Singer, A. (1995). Perfectionism and parental authority styles. Individual Psychology, 51(1), 50-60.

Fong, R. W., \& Yuen, M. (2011). Perfectionism in Chinese elementary school students: Validation of the Chinese Adaptive/Maladaptive Perfectionism Scale. Talent Development and Excellence, 3(2), 203-213.

Fong, R. W., \& Yuen, M. (2013a). Perfectionism, connectedness and academic self-efficacy in academically talented primary school students in Hong Kong. Manuscript submitted for publication.

Fong, R. W., \& Yuen, M. (2013b). Perfectionism, connectedness and academic self-efficacy in academically talented primary school students in Hong Kong: A qualitative investigation. Manuscript submitted for publication.

Franche, V., Gaudreau, P., \& Miranda, D. (2012). The $2 \times 2$ model of perfectionism: A comparison across Asian Canadians and European Canadians. Journal of Counseling Psychology, 59(4), $567-574$.

Frost, R. O., Heimberg, R. G., Holt, C. S., Mattia, J. I., \& Neubauer, A. L. (1993). A comparison of two measures of perfectionism. Personality and Individual Differences, 14, 119-126.

Frost, R. O., Marten, P. A., Lahart, C. M., \& Rosenblate, R. (1990). The dimensions of perfectionism. Cognitive Therapy and Research, 14, 449-468. doi:10.1007/BF01172967

Fung, H. (1999). Becoming a moral child: The socialization of shame among young Chinese children. Ethos, 27(2), 180-209. doi:10.1525/eth.1999.27.2.180

Fursland, A., Raykos, B., \& Steele, A. (2009). Perfectionism in perspective. Perth, WA: Centre for Clinical Interventions.

Gnilka, P. B., Ashby, J. S., \& Noble, C. M. (2012). Multidimensional perfectionism and anxiety: Differences among individuals with perfectionism and tests of a coping-mediation model. Journal of Counseling \& Development, 90(40), 427-436. 
Greenspon, T. S. (2000). "Healthy perfectionism" is an oxymoron! Reflections on the psychology of perfectionism and the sociology of science. Journal of Secondary Gifted Education, 11(4), 197-208.

Gross, M. U. M. (2002). Social and emotional issues for exceptionally intellectually gifted students. In M. Neihart, S. Reis, N. Robinson, \& S. Moon (Eds.), Social and emotional development of gifted children (pp. 19-29). Waco, Texas: Prufrock Press Inc.

Gross, M. U. M. (1989). The pursuit of excellence or the search for intimacy? The forced-choice dilemma of gifted youth. Roeper Review, 11,189-194.

Hamachek, D. E. (1978). Psychodynamics of normal and neurotic perfectionism. Psychology, 15, 27-33.

Hau, K. T., \& Salili, F. (1991). Prediction of academic performance among Chinese students: Effort can compensate for lack of ability. Organizational Behavior and Human Decision Processes, $65,83-94$.

Hebert, T. P., \& Speirs Neumeister, K. L. (2002). Fostering the social and emotional development of gifted children through guided viewing of film. Roeper Review, 25(1), 17-21.

Hewitt, P. L., Caelian, F. C., Flett, F. G., Sherry, B. S., Collins, L., \& Flynn, A. C. (2002). Perfectionism in children: Associations with depression, anxiety, and anger. Personality and Individual Differences, 32, 1049-1056.

Hewitt, P. L., \& Flett, G. L. (1991). Perfectionism in the self and social contexts: conceptualization, assessment, and association with psychopathology. Journal of Personality and Social Psychology, 60, 456-470.

Hewitt, P. L., Flett, G. L., Sherry, S., \& Caelian, C. (2006). Trait perfectionism dimensions and suicidal behavior. In T. Ellis (Eds.), Cognition and suicide: Theory, research, and therapy (pp. 215-235). Washington, DC: American Psychological Association.

Ho, D. Y. F. (1994). Cognitive socialization in Confucian heritage cultures. In P. Greenfield \& R. Cocking (Eds.), The development of the minority child: Culture in and out of context (pp. 
285-313). Hillsdale, NJ: Erlbaum.

Ho, D. Y. F., \& Chiu, C.-Y. (1994). Component ideas of individualism, collectivism, and social organization: An application in the study of Chinese culture. In U. Kim, H. C. Triandis, C. Kagitcibasi, S.-C. Choi, \& G, Yoon (Eds.), Individualism and collectivism: Theory, method and applications (pp. 137-156). Thousand Oaks, CA: Sage.

Hollingworth, L. S. (1942). Children above IQ 180: Their origin and development. New York: World Books.

Kashdan, T. B., \& Yuen, M. (2007). Whether highly curious students thrive academically depends on perceptions about the learning environment: A study of Hong Kong adolescents. Motivation and Emotion, 31(4), 260-270.

Kawamura, K. Y., Frost, R. O., \& Harmatz, M. G. (2002). The relationship of perceived parenting styles to perfectionism. Personality and Individual Differences, 32, 317-327.

Kottman, T., \& Ashby, J. S. (2000). Perfectionistic children and adolescents: Implications for school counselors. Professional School Counseling, 3(3), 182-188.

Lau, P. S. Y. (2000). Practicing counseling in Chinese communities: Some reflections on cultural competence and indigenization. Asian Journal of Counselling, 7(1), 43-52.

Lerouxa, J. A., \& Levitt Perlman, M. (2000). The gifted child with attention deficit disorder: An identification and intervention challenge. Roeper Review, 22(3), 171-176.

Li, J. (2002). A Cultural Model of Learning: Chinese "Heart and Mind for Wanting to Learn". Journal of Cross-Cultural Psychology, 33(3), 248-269.

Lieber, E., Fung, H., \& Leung, P. W.-L. (2006). Chinese child-rearing beliefs: Key dimensions and contributions to the development of culture-appropriate assessment. Asian Journal of Social Psychology, 9(2), 140-147.

LoCicero, K., \& Ashby, J. S. (2000). Multidimensional perfectionism in middle school age gifted students: A comparison to peers from general cohort. Roeper Review, 22(3), 182-185.

McBride-Chang, C., \& Chang, L. (1998). Adolescent-parent relations in Hong Kong: Parenting 
styles, emotional autonomy, and school achievement. Journal of Genetic Psychology, 159(4), 421-436.

Miller, L., Lambert, A., \& Speirs Neumeister, K. L. (2012). Parenting style, perfectionism, and creativity in high-ability and high-achieving young adults. Journal for the Education of the Gifted, 35(4), 344-365.

Mobley, M., Slaney, R. B., \& Rice, K. G. (2005). Cultural validity of the Almost Perfect Scale Revised for African American college students. Journal of Counseling Psychology, 52(4), 629-639.

Mofield, E. L., \& Chakraborti-Ghosh, S. (2010). Addressing multidimensional perfectionism in gifted adolescents with affective curriculum. Journal for the Education of the Gifted, 33(4), 479-513.

Mohamadi, F. S., Farghadani, A., \& Shahmohamadi, Z. (2012). Individual factors antecedents of academic procrastination: The role of perfectionism components and motivational beliefs in predicting of students procrastination. European Journal of Social Sciences, 30(2), 330-338.

Nakano, K. (2009). Perfectionism, self-efficacy, and depression: Preliminary analysis of the Japanese version of the Almost Perfect Scale-Revised. Psychological Reports, 104(3), 896-908.

Neihart, M. (1999). The impact of giftedness on psychological well-being: What does the empirical literature say? Roeper Review, 22, 10-17.

Neihart, M., Reis, S. M., Robinson, N. M., \& Moon, S. M. (2002). The social and emotional development of gifted children: What do we know? Waco, TX: Prufrock Press.

Ng, F. F., Pomerantz, E. M., \& Lam, S. (2007). European American and Chinese parents' responses to children's success and failure: Implications for children's responses. Developmental Psychology, 43(5), 1239-1255.

Nugent, S.A. (2000). Perfectionism: Its manifestations and classroom-based interventions. Journal of Advanced Academics, 11, 4, 215-221. 
O'Connor, R. C., Rasmussen, S., \& Hawton, K. (2010). Predicting depression, anxiety and self-harm in adolescents: The role of perfectionism and acute life stress. Behaviour Research and Therapy, 48(1), 52-59.

Orange, C. (1997). Gifted students and perfectionism. Roeper Review, 20, 39-41.

Owen, R. G. \& Slade, P. D. (2008). So perfect it's positively harmful? Reflections on the adaptiveness and maladaptiveness of positive and negative perfectionism. Behavioral Modification, 32(6), 928-937.

Pacht, A. R. (1984). Reflections on perfection. American Psychologist, 39, 386-390.

Parker, W. D. (2000). Healthy perfectionism in the gifted. Journal of Secondary Gifted Education, 11(4), 173-182.

Parker, W. D., \& Mills, C.J. (1996). The incidence of perfectionism in gifted students. Gifted Child Quarterly, 40(4), 194-199. doi: 10.1177/001698629604000404

Parker, W. D., \& Stumpf, H. (1995). An examination of the Multidimensional Perfectionism Scale with a sample of academically talented children. Journal of Psychoeducational Assessment, $13,372-383$.

Peterson, J. S. (2009). Myth 17: Gifted and talented individuals do not have unique social and emotional needs. Gifted Child Quarterly, 53(4), 280-282.

Peterson, G. W., Cobas, J. A., Bush, K. R., Supple, A., \& Wilson, S. M. (2005). Parent-youth relationships and the self-esteem of Chinese adolescents: Collectivism versus individualism. Marriage \& Family Review, 36(3-4), 173-200.

Pfeiffer, S. I., Stocking, V. B. (2000). Vulnerabilities of academically gifted students. Special Services in the Schools, 16(1-2), 83-93.

Piechowski, M. M. (1997). Emotional giftedness: The measure of intrapersonal intelligence. In N. Colangelo \& G. A. Davis (Eds.), Handbook of gifted education (2nd ed., pp. 366-381). Boston: Allyn and Bacon.

Preusser, K. J., Rice, K. G., \& Ashby, J. S. (1994). The role of self-esteem in mediating the 
perfectionism-depression connection. Journal of College Student Development, 35, 88-93.

Rasmussen, S. A., Elliott, M. A., \& O’Connor, R. C. (2012). Psychological distress and perfectionism in recent suicide attempters: The role of behavioural inhibition and activation. Personality and Individual Differences, 52(6), 680-685.

Rice, K. G., Ashby, J. S., \& Gilman, R. (2011). Classifying adolescent perfectionists. Psychological Assessment, 23(3), 563.

Rice, K. G., Leever, B. A., Noggle, C. A., \& Lapsley, D. K. (2007). Perfectionism and depressive symptoms in early adolescence. Psychology in the Schools, 44, 139-155.

Rice, K. G., \& Preusser, K. J. (2002). The Adaptive/Maladaptive Perfectionism Scale. Measurement and Evaluation in Counseling and Development, 34, 210-222.

Rice, K. G., Richardson, C. M., \& Clark, D. (2012). Perfectionism, procrastination, and psychological distress. Journal of Counseling Psychology, 59(2), 288.

Rice, K. G., \& Slaney, R. B. (2002). Clusters of perfectionists: Two studies of emotional adjustment and academic achievement. Measurement and Evaluation in Counseling and Development, $35,35-48$.

Robinson, N. M. (2002). Individual differences in gifted students' attributions for academic performances. In M. Neihart, S. Reis, N. Robinson, \& S. Moon (Eds.), Social and emotional development of gifted children (pp. 61-70). Waco, Texas: Prufrock Press.

Roedell, W. C. (1984). Vulnerabilities of highly gifted children. Roeper Review, 6(3), 127-130.

Salili, F. (1994). Age, sex, and cultural differences in the meaning and dimensions of achievement. Personality and Social Psychology Bulletin, 20(6), 648-661.

Schuler, P. A. (2000). Perfectionism in the gifted adolescent. Journal of Secondary Gifted Education, 11, 183-196.

Seo, E. H. (2008). Self-efficacy as a mediator in the relationship between self-oriented perfectionism and academic procrastination. Social Behavior and Personality, 36(6), 753-764. 
Shim, S. S., \& Fletcher, K. L. (2012). Perfectionism and social goals: What do perfectionists want to achieve in social situations? Personality and Individual Differences, 52, 919-924.

Silverman, L.K. (1990). Issues in affective development of the gifted. In J. VanTassel-Baska (Ed.), A practical guide to counseling the gifted in a school setting (pp. 15-30). Reston, VA: Council for Exceptional Children.

Silverman, L. K. (1993). Counseling the gifted and talented. Denver, CO: Love.

Silverman, L.K. (1999). Perfectionism: The crucible of giftedness. Advanced Development, 8, 47-61.

Slade, P. D., \& Owens, G. R. (1998). A dual process model of perfectionism based on reinforcement theory. Behavior Modification, 3, 372-390

Slaney, R. B., Rice, K. G., Mobley, M., Trippi, J., \& Ashby, J. S. (2001). The revised Almost Perfect Scale. Measurement and Evaluation in Counseling and Development, 34, 130-145.

Speirs Neumeister, K. L. (2004a). Factors influencing development of perfectionism in gifted college students. Gifted Child Quarterly, 48(4), 16.

Speirs Neumeister, K. L. (2004b). Understanding the relationship between perfectionism and achievement motivation in gifted college students. Gifted Child Quarterly, 48(3), 219-231.

Speirs Neumeister, K. L. (2007). Perfectionism in gifted students: An overview of current research. Gifted Education International, 23(3), 254-263.

Speirs Neumeister, K. L., \& Finch, H. (2006). Perfectionism in high-ability students: Relational precursors and influences on achievement motivation. Gifted Child Quarterly, 50(3), 238-251.

Speirs Neumeister, K. L. S., Williams, K. K., \& Cross, T. L. (2009). Gifted High-School Students' Perspectives on the Development of Perfectionism. Roeper Review, 31(4), 198-206.

Stankov, L. (2010). Unforgiving Confucian culture: A breeding ground for high academic achievement, test anxiety and self-doubt? Learning and Individual Differences, 20, 555-563.

Stoeber, J., \& Eismann, U. (2007). Perfectionism in young musicians: Relations with motivation, effort, achievement, and distress. Personality and Individual Differences, 43(8), 2182-2192. 
Stoeber, J., Feast, A. R., \& Hayward, J. A. (2009). Self-oriented and socially prescribed perfectionism: Differential relationships with intrinsic and extrinsic motivation and test anxiety. Personality and Individual Differences, 47(5), 423-428.

Stoeber, J., Hoyle, A., \& Last, F. (2013). The Consequences of Perfectionism Scale: Factorial structure and relationships with perfectionism, performance perfectionism, affect, and depressive symptoms. Measurement and Evaluation in Counseling and Development.

Stoeber, J., Kobori, O., \& Tanno, Y. (2013). Perfectionism and self-conscious emotions in Bristish and Japanese students: Predicting pride and embarrassment after success and failure. European Journal of Personality, 27, 59-70.

Stoeber, J., Otto, K. (2006). Positive conceptions of perfectionism: Approaches, evidence, challenges. Personality and Social Psychology Review, 10(4), 295-319.

Stoeber, J., \& Stoeber, F. S. (2009). Domains of perfectionism: Prevalence and relationships with perfectionism, gender, age, and satisfaction with life. Personality and Individual Differences, $46(4), 530-535$.

Stoeber, J., Stoll, O., Pescheck, E., \& Otto, K. (2008). Perfectionism and achievement goals in athletes: Relations with approach and avoidance orientations in mastery and performance goals. Psychology of Sport and Exercise, 9(2), 102-121.

Stornelli, D., Flett, G. L., \& Hewitt, P. L. (2009). Perfectionism, achievement, and affect in children: A comparison of students from gifted, arts, and regular programs. Canadian Journal of School Psychology, 24(4), 267-283.

Sue, S., \& Okazaki, S. (1990). Asian-American educational achievements: A phenomenon in search of an explanation. American Psychologist, 45(8), 913-920.

Swiatek, M. A. (1995). An empirical investigation of the social coping strategies used by gifted adolescents. Gifted Child Quarterly, 39, 154-161. 
Swiatek, M.A. (2003). Perfectionism and the gifted: What's good, what's bad? Online document from Carnegie Mellon Institute for Talented Elementary and Secondary Students, accessed 20 January 2012 at: http://www.cmu.edu/cmites/perfectionism.html

Tannenbaum, A. J. (1997). The meaning and making of giftedness. In N. Colangelo \& G. A. Davis (Eds.), Handbook of gifted education (2 ${ }^{\text {nd }}$ ed., pp. 27-42). Boston: Allyn and Bacon.

Tobin, J. J., Wu, D. Y. H., \& Davidson, D. H. (1989). Preschool in three cultures. New Haven, CT: Yale University Press.

Tweed, R. G., \& Lehman, D. R. (2002). Learning considered within a cultural context: Confucian and Socratic approaches. American Psychologist, 57(2), 89-99.

Vohs, K. D., Bardone, A. M., Joiner Jr, T. E., \& Abramson, L. Y. (1999). Perfectionism, perceived weight status, and self-esteem interact to predict bulimic symptoms: A model of bulimic symptom development. Journal of Abnormal Psychology, 108(4), 695.

Wang, K. T. (2012). Personal and family perfectionism of Taiwanese college students: Relationships with depression, self-esteem, achievement motivation, and academic grades. International Journal of Psychology, 47(4), 305-314.

Wang, K. T., Fu, C. C., \& Rice, K. G. (2012). Perfectionism in gifted students: Moderating effects of goal orientation and contingent self-worth. School Psychology Quarterly, 27(2), 96-108.

Wang, K. T., Puri, R., Slaney, R. B., Methikalam, B., \& Chadha, N. (2012). Cultural Validity of Perfectionism Among Indian Students Examining Personal and Family Aspects Through a Collectivistic Perspective. Measurement and Evaluation in Counseling and Development, $45(1), 32-48$.

Wang, K. T., Slaney, R. B., \& Rice, K. G. (2007). Perfectionism in Chinese university students from Taiwan: A study of psychological well-being and achievement motivation. Personality and Individual Differences, 42, 1279-1290.

Wang, K. T., Yuen, M., \& Slaney, R.B. (2008). Perfectionism, depression, loneliness, and life satisfaction: A study of high school students in Hong Kong. The Counseling Psychologist, 
37(2), 249-274.

Watson, B. (2007). The Analects of Confucius. New York: Columbia University Press.

Weiner, B. A., \& Carton, J. S. (2011). Avoidant coping: A mediator of maladaptive perfectionism and test anxiety. Personality and Individual Differences, 52(5), 632-636.

Winner, E. (2000). The origins and ends of giftedness. American Psychologist, 55(1), 159-169.

Yoon, J., \& Lau, A. S. (2008). Maladaptive perfectionism and depressive symptoms among Asian American College students: Contributions of interdependence and parental relations. Cultural Diversity and Ethnic Minority Psychology, 14(2), 92-101.

Zhang, Y., Gan, Y., \& Cham, H. (2007). Perfectionism, academic burnout and engagement among Chinese college students: A structural equation modeling analysis. Personality and Individual Differences, 43, 1529-1540.

Zi, F. (2003). The patterns of perfectionism in Chinese graduate students and their relationship with educational environment, personality, and engagement, and creativity. Unpublished doctoral dissertation, University of Georgia. 